\title{
3 Research Square

\section{Molecular Characterization of Chikungunya Virus Isolates From Two Localized Outbreaks During 2014-2019 in Kerala, India}

\section{Anukumar Balakrishnan ( $\square$ anukumar74@gmail.com )}

National institute of virology https://orcid.org/0000-0002-2958-4391

Asia Devi Thounaojam

National Institute of Virology

Aishwarya Babu

National Institute of Virology

Jijo Koshy

National Institute of Virology

Nikhil T L

National Institute of Virology

Sugunan Attayur Purushottaman

Regional Medical Research Centre Port Blair

\section{Research Article}

Keywords: Chikungunya virus, phylogenetic analysis, Kerala outbreak, Indian ocean lineage

Posted Date: February 15th, 2021

DOI: https://doi.org/10.21203/rs.3.rs-223462/v1

License: (c) (i) This work is licensed under a Creative Commons Attribution 4.0 International License.

Read Full License

Version of Record: A version of this preprint was published at Archives of Virology on August 5th, 2021.

See the published version at https://doi.org/10.1007/s00705-021-05186-9. 


\section{Abstract}

After the 2005-2009 chikungunya epidemic, intermittent outbreaks were reported in many parts of India. The outbreaks were caused by either locally circulating strains or imported viruses. Virus transmission route can be traced by complete genome sequencing studies. We investigated two outbreaks in the year 2014 and 2019 in Kerala, India. The chikungunya virus (CHIKV) was isolated from the samples and whole genome was sequenced for a 2014 isolate and a 2019 isolate. The phylogenetic tree revealed that the isolates formed a separate group with 2019 isolate from Pune, Maharashtra and belonged to the East/ Central/ South African (ECSA) genotype, Indian subcontinent sub lineage of Indian Ocean Lineage (IOL). A novel mutation at amino acid position 76 of E2 gene was observed in the group. The phylogenetic results suggest that the outbreaks might have caused by a virus, which has been circulating in India since 2014. Furthermore a detailed study is necessary to find out the evolution of CHIKV in India.

\section{Introduction}

Chikungunya virus (CHIKV) is an enveloped, single-stranded positive sense RNA virus that belongs to the Togaviridae family alphavirus genus. The virus genome size is around $12 \mathrm{~kb}$, and has two open reading frames (ORF) ORF 1, and ORF 2. ORF 1 codes for the non-structural proteins (nsP); nsP1, nsP2, nsP3 and nsP4 while ORF 2 codes for five structural proteins E1, E2, E3, C (capsid), and 6K [1]. The genotype of $\mathrm{CHIKV}$ is determined based on sequencing of the gene E1. CHIKV has three distinct genotypes; West African (WA), East/Central/South African (ECSA), and Asian [2]. These genotypes represent the independent evolution of the virus in different geographical regions. Evolutionary studies have revealed that WA genotype originated in Africa and subsequently moved into Asia where it evolved into Asian genotype. The Indian Ocean lineage (IOL) within the ECSA genotype was responsible for the Reunion Island outbreak in 2005 [3]. In Asia, the CHIKV was first isolated in Bangkok, Thailand in 1958. In India the first outbreak was recorded in Kolkata during 1963. It spread to the states of Tamil Nadu, Andra Pradesh, and Maharashtra during 1964 to 1965 and disappeared in 1973. Earlier outbreaks in India were caused by Asian genotype [4]. In 2004, there was a major outbreak in Kenya and in 2005 it spread to La Reunion via neighboring islands. Afterwards the virus spread across several islands in Indian Ocean and India. In India, the virus re-emerged in 2006 after a gap of 32 years and caused an explosive outbreak that affected 13 states. Andhra Pradesh, Karnataka, Maharashtra, Madhya Pradesh, Tamil Nadu, Gujarat, and Kerala were the mainly affected states. The isolates of virus belonged to the ECSA genotype [5]. In 2007 it spread from India to Sri Lanka, Thailand, Malaysia, and Italy. In La Reunion islands, the second outbreak occurred in the year 2009 and contributed to the 2010 outbreak in Europe. The circulation of CHIKV has been recorded during 2011 and 2012 in many countries of central Africa, Western Africa, Oceania, Southern and Southeastern Asia (SEA), Europe and Western Indian Ocean islands. The Asian genotype continues to circulate in the regions of SEA and the Western Pacific [6]. Pyke et al. (2018) reported a case of Asian genotype CHIKV imported from the Philippines into Australia in 2016 [7]. The Indian subcontinent sub lineage within the IOL of the ECSA genotype continues to circulate in India and surrounding countries [8]. 
Following 2006-2009 CHIKV epidemic, India recorded several outbreaks every year (IDSP: www.idsp.nic.in). Two CHIKV outbreaks occurred in two separate locations in the state of Kerala between 2014 and 2019. The outbreaks were attended to obtain epidemiological details, as well as acute samples for virus isolation. The present study was carried out to perform molecular characterization of CHIKV responsible for the outbreaks in Kerala between 2014 and 2019. Molecular characterization of virus genome is important for studying the molecular epidemiology of the virus. Virus evolved with occurrence of many synonymous and non-synonymous mutations in the structural and non structural genes during subsequent outbreaks. Some of the mutations were known to improve the virus fitness [9].

\section{Materials And Method Source of isolates}

The first outbreak was occurred in Mattancherry ward under Cochin Municipal Corporation in Ernakulum district during the year 2014. Indian Council of Medical Research (ICMR)-National Institute of Virology (NIV), Kerala unit, a state level viral diagnostics and research laboratory, investigated the outbreak. A house to house survey was carried out in 11 colonies $(n=305$ houses) and blood samples were collected from 197 suspected individuals. All specimens were subjected to ELISA in order to test the presence of anti-CHIKV and anti-dengue (DENV) IgM antibodies using in house IgM capture- ELISA kit. The samples $(n=52)$ collected within 7 days post onset of fever were tested for CHIKV by real-time RT-PCR as described earlier (Carletti et al 2007). RNA was extracted from $50 \mu \mathrm{l}$ of the serum sample using the MagMax Viral RNA isolation kit (Ambion, ABI, USA) and used in real-time RT-PCR. Samples, which were positive by CHIKV real-time RT-PCR, were subjected to virus isolation.

The second outbreak occurred in Rosapookandam area, Kumily, Idukki district during the year 2019. Seven localities in the area were investigated. In each locality ten houses were visited and a total of 59 samples were collected. All the samples were processed for anti-CHIKV and anti-DENV IgM ELISA. Three acute samples were processed for CHIKV real-time RT-PCR and positive sample/s were subjected to virus isolation.

Virus isolation: Virus isolation was performed in Vero cells. Briefly, 80-90\% confluent monolayer of Vero cells in the 6- well tissue culture plate was inoculated with $200 \mu \mathrm{L}$ of 1:1 diluted human patient sera in serum free DMEM medium. The plate was incubated at $37^{\circ} \mathrm{C}$ for an hour with intermittent shaking for virus adsorption. After incubation, two $\mathrm{ml}$ of DMEM with $2 \%$ foetal bovine serum (FBS) was added to each well. The plate was further incubated at $37^{\circ} \mathrm{C}$ with $5 \% \mathrm{CO}_{2}$. The plate was observed for 6 to 7 days for the appearance of $70-80 \%$ cytopathic effect (CPE). The samples negative for the first passage were further processed by two blind passages in Vero cells.

\section{Genome sequencing}


Primers sequence covering the entire length of genome were synthesised as described earlier [10]. Four fragments of approximately $2-4$ kbs were amplified (Table 1). Virus infected culture supernatant was used as a source of viral RNA. The viral RNA was extracted from $140 \mu \mathrm{l}$ of culture supernatant using QIAmp viral RNA mini kit as per the manufacturer's protocol. The RNA was eluted in nuclease free water with the volume of $50 \mu \mathrm{l}$. The complementary DNA (CDNA) was synthesized and the fragments were amplified using Taq DNA polymerase (Cat.No.R001A, TaKaRa Bio, Japan) as per the manufacturer's instruction. The amplified PCR products were gel purified using NucleoSpin Gel and PCR clean-up kit. Sequencing was outsourced to ThermoFisher Scientific Ltd, India, using ion-torrent next generation sequencing platform.

Table 1

Primer details for full length sequencing of Chikungunya virus and PCR conditions

\begin{tabular}{|c|c|c|c|c|}
\hline Fragment & $\begin{array}{l}\text { Primer } \\
\text { name }\end{array}$ & Sequence & $\begin{array}{l}\text { Product } \\
\text { size }\end{array}$ & $\begin{array}{l}\text { Annealing } \\
\text { temperature }\end{array}$ \\
\hline \multirow[t]{2}{*}{1} & $1 \mathrm{~F}$ & $\begin{array}{l}5^{\prime}- \\
\text { gccggggcccaaagagacacgtagccta- } \\
3^{\prime}\end{array}$ & \multirow[t]{2}{*}{$2.3 \mathrm{~kb}$} & \multirow[t]{2}{*}{$64{ }^{\circ} \mathrm{C}$} \\
\hline & $1 \mathrm{R}$ & 5'-gttggatatctctagacctctctgtct-3' & & \\
\hline \multirow[t]{2}{*}{2} & $2 \mathrm{~F}$ & 5'-gcaagatatctgcacgtacggttgatt-3' & \multirow[t]{2}{*}{$2.8 \mathrm{~kb}$} & \multirow[t]{2}{*}{$62{ }^{\circ} \mathrm{C}$} \\
\hline & $2 \mathrm{R}$ & $5^{\prime}$-cttacggccgcaaggtttccgattgtg-3' & & \\
\hline \multirow[t]{2}{*}{3} & $5065 \mathrm{~F}$ & 5'-tgtacaggaagcgagtacgacc-3' & \multirow[t]{2}{*}{$3.0 \mathrm{~kb}$} & \multirow[t]{2}{*}{$50^{\circ} \mathrm{C}$} \\
\hline & $8034 R$ & 5'-ccgcttaaaggccaatttg-3' & & \\
\hline \multirow[t]{2}{*}{4} & $7910 \mathrm{~F}$ & 5'-tcgaagtcaagcacgaagg-3' & \multirow[t]{2}{*}{$3.9 \mathrm{~kb}$} & \multirow[t]{2}{*}{$50^{\circ} \mathrm{C}$} \\
\hline & $11770 \mathrm{R}$ & 5'-tttgccaattatggtattca-3' & & \\
\hline
\end{tabular}

\section{Phylogenetic analysis}

Phylogenetic analysis was performed using MEGA 7.0 software [11]. Full genome sequences $(n=32)$ available in the GenBank representing all three genotypes were retrieved for analysis. The 32 sequences consisted of sequences from Kerala and other parts of India and sequences from the neighbouring countries. The sequences obtained from GenBank were aligned using ClustalW mode in the MEGA v 7.0.26 software. Phylogenetic tree was constructed using Maximum Likelihood method implemented in the MEGA software. Genetic distances were calculated using the Tamura Nei Model of nucleotide substitution. The robustness of the resulting tree was assessed with 1000 bootstrap replicates.

\section{Result}

Of the 52 samples tested by real-time RT-PCR from the 2014 outbreak, 14 samples showed the presence of CHIKV RNA. CHIKV was successfully isolated from 12 samples. In the 2019 outbreak, one sample 
turned positive for CHIKV PCR out of three acute samples. The virus was isolated from the PCR positive sample. One isolate from each outbreak was subjected to sequencing.

The complete genome of the virus was sequenced using lon Torrent next generation sequencing technology. The sequences were aligned in MEGA software. For mutation analysis, all the sequences were matched with reference virus, the South African strain S27. The synonymous and non-synonymous mutations were identified and sequences compared. The phylogenetic tree revealed that the Kerala isolates (2014 \& 2019) belonged to the ECSA genotype, and the IOL lineage Indian subcontinent sub lineage (Fig. 1).

With reference to the prototype virus, the 2014 Kerala isolate had $0.72 \%$ non-synonymous and $2.4 \%$ synonymous mutations while the 2019 isolate had $0.62 \%$ non-synonymous and $2.63 \%$ synonymous mutation. The phylogenetic tree showed that both the 2014 and 2019 Kerala isolates clustered along with isolate of Pune 2019 and formed a separate group. This group has a common mutation, E2: A 76 T, which was absent, in other viruses analyzed in this study (Supp.Table 1).

In the 2014 Kerala isolate, a novel mutation was observed in nsP1 gene (A 10 T). Likewise five nonsynonymous mutations in nsP2 gene and one each in nsP3 \& nsP4 genes were also observed. Two novel mutations were observed in E2 (Q 158 R and R $395 \mathrm{I}$ ). A novel mutation was noticed in capsid region ( $\mathrm{N}$ 79 S) in the 2019 isolate.

In both 2014 and 2019 isolates the E1: A 226 V mutation was absent. However, the other mutations that is E1: M 269 V, D $284 \mathrm{E}, \mathrm{K} 211 \mathrm{E}$ were present. The E2: V $264 \mathrm{~A}$ and I $211 \mathrm{~T}$ mutations were also present in both the isolates (Supp.Table 1).

\section{Discussion}

Full genome sequences of the virus isolates are indispensable for molecular epidemiology studies. There is dearth of full genome sequences of recent CHIKV isolates from Kerala. The sequence data from the present study will improve our understanding of CHIKV strains circulating in Kerala with regard to its genetic evolution in different parts of the country. During 2005, CHIKV resurfaced in India and affected many south Indian states and the epidemics extended until 2009. Since then there have been many sporadic outbreaks in many places in India. We had a chance to attend two such outbreaks in Kerala. We could isolate the virus from PCR positive samples and sequenced the full genome of two isolates.

The phylogenetic analysis revealed a novel mutation in the E2 gene A $76 \mathrm{~T}$ is the signature trait of the isolates. The mutation falls in the region E2: $52-82$ at the top of the spike in domain A, which is exposed and reported to be the point of contact for cellular receptors. This domain is more stable and exposed in the mature conformation, which might be beneficial for host-cell binding [12].

The common mutation A $226 \mathrm{~V}$, which confers the virus, the ability to adopt to Aedes albopictus was not observed but there were two other mutations E1: M 269 V, D 284 E were observed. The E1: A 226 V, M 
269 V, \& D 284 E mutations were considered to be a molecular signature of IOL [13]. The CHIKV outbreak occurred in Pune and Kerala in the same time during 2019. The Pune 2019 isolate is very close to Kerala 2019 isolate and share the common ancestor.

New Delhi 2010 isolate, which was suspected to be a source for outbreak in India and neighbouring countries, did not form the cluster with recent isolates [14]. Previous phylogeography study revealed that geographical ancestry of the IOL lineage to Kenya around 2004 [15]. The study by Chen et al, 2016 revealed that India has been a source for the radiation of CHIKV causing outbreaks in surrounding countries and IOL strains have established persistent transmission in Southeast Asian countries including Thailand [16]. Another Indian study also suggested that IOL lineage from India is associated with persistent global transmissions [8]. However, the unique mutation E2: A 76 T in 2014 \& 2019 Kerala isolates, which is absent in other strains except Pune 2019 isolate indicate that the same virus was in circulation in Kerala from 2014 to 2019. The resurgence of CHIKV outbreaks in these regions may be attributed to indigenous evolution rather than importations.

To conclude, the present study improved our understanding of CHIKV strains circulating in Kerala, India during 2014 to 2019 in the light of their genetic variability compared to CHIKV from other parts of the world. The significance of E2 mutation A $76 \mathrm{~T}$ to the $\mathrm{CHIKV}$ requires thorough research.

\section{Declarations}

\section{Acknowledgements}

The author acknowledges the Department of Health Research for financial support the study through extramural funding. We thank the Director, National Institute of Virology and NIV Kerala team specially Mrs.Sreelekha and Kunjila K for all the support during the study. We also thank the institute manuscript review committee members Drs.Bondre, Vaidya, Gurav, Alagarasu and Sarah Cherian for critical comments and suggestions. Our special gratitude goes to ThermoFisher Scientific India Ltd and the team for sequencing work.

\section{References}

1. Galán-Huerta KA, Rivas-Estilla AM, Fernández-Salas I, Farfan-Ale JA, Ramos-Jiménez J (2015) Chikungunya virus: A general overview. Med Univ 17(68):175-183

2. Volk SM, Chen R, Tsetsarkin KA, Adams AP, Garcia TI, Sall AA et al (2010) Genome-scale phylogenetic analyses of chikungunya virus reveal independent emergences of recent epidemics and various evolutionary rates. J Virol 84(13):6497-6504

3. Mascarenhas M, Garasia S, Berthiaume P, Corrin T, Greig J, Ng V et al (2018) A scoping review of published literature on chikungunya virus. PLOS ONE 13(11):e0207554

4. Lahariya C, Pradhan SK (2006) Emergence of chikungunya virus in Indian subcontinent after 32 years: a review. J Vect Born Dis 43:151-156 
5. Kalantri SP, Joshi R, Riley LW (2006) Chikungunya epidemic: An Indian perspective. Natl Med J INDIA 19(6):9

6. Diop D, Meseznikov G, Sanicas M (2015) Chikungunya outbreaks from 2000 to 2015: a review. MOJ Public Health 2(6):181-187

7. Pyke AT, Moore PR, McMahon J (2018) New insights into chikungunya virus emergence and spread from Southeast Asia. Emerg Microbes Infect 7(1):1-3

8. Newase P, More A, Patil J, Patil P, Jadhav S, Alagarasu K et al (2020) Chikungunya

9. phylogeography reveals persistent global transmissions of the Indian Ocean Lineage from

10. India in association with mutational fitness. Infect Genet Evol 82:104289

11. Domingo E, Holland JJ (1997) RNA virus mutations and fitness for survival. Annu Rev Microbiol 51(1):151-178

12. Stapleford KA, Moratorio G, Henningsson R, Chen R, Matheus S, Enfissi A et al (2016) Whole-Genome Sequencing Analysis from the Chikungunya Virus Caribbean Outbreak Reveals Novel Evolutionary Genomic Elements. PLOS Negl Trop Dis 10(1):e0004402

13. Kumar S, Stecher G, Tamura K (2016) MEGA7: Molecular Evolutionary Genetics Analysis Version 7.0 for Bigger Datasets. Mol Biol Evol 33(7):1870-1874

14. Bordi L, Carletti F, Lalle E, Colavita F, Meschi S, Di Caro A et al (2018) Molecular Characterization of Autochthonous Chikungunya Cluster in Latium Region, Italy. Emerg Infect Dis 24(1):178-180

15. Niyas KP, Abraham R, Unnikrishnan R, Mathew T, Nair S, Manakkadan A et al (2010) Molecular characterization of Chikungunya virus isolates from clinical samples and adult mosquitoes emerged from larvae from Kerala, South India. Virol J 7(1):189

16. Afreen N, Deeba F, Khan WH, Haider SH, Kazim SN, Ishrat R et al (2014) Molecular characterization of dengue and chikungunya virus strains circulating in New Delhi, India: DENV and CHIKV strains from India. Microbiol Immunol 58(12):688-696

17. Wahid B, Ali A, Rafique S, Idrees M (2017) Global expansion of chikungunya virus: mapping the 64year history. Int J Infect Dis 58:69-76

18. Chen R, Puri V, Fedorova N, Lin D, Hari KL, Jain R et al (2016) Comprehensive Genome Scale Phylogenetic Study Provides New Insights on the Global Expansion of Chikungunya Virus. J Virol 90(23):10600-10611

\section{Figures}




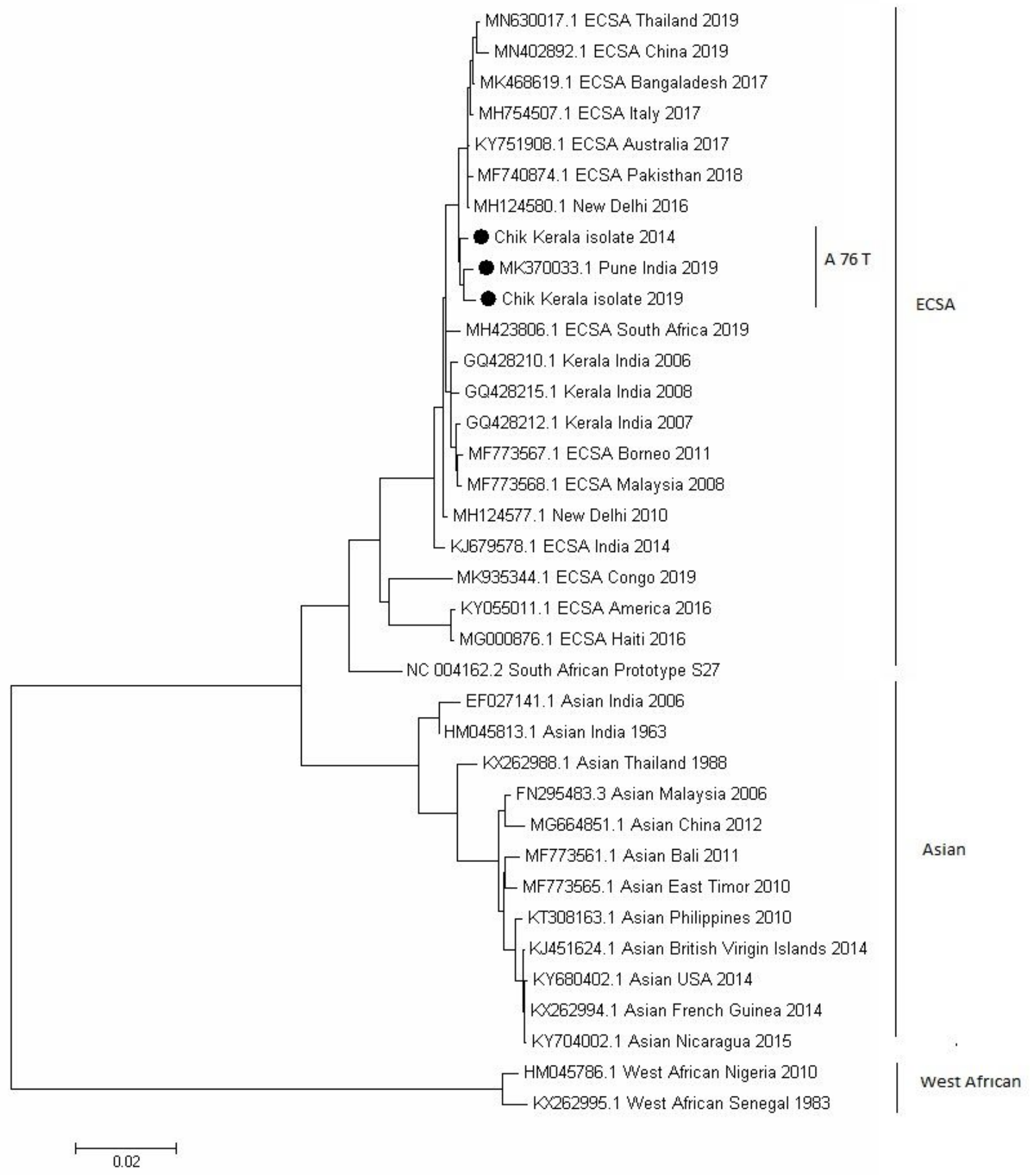

\section{Figure 1}

Phylogenetic tree highlighting the position of CHIKV Kerala isolates relative to other CHIKV sequences. Sequences were aligned using CLUSTALW (1000 bootstrap replicates), and phylogenetic inferences were obtained using the maximum-likelihood method within the MEGA7. The scale bar corresponds to 0.02 change per nucleotide. 


\section{Supplementary Files}

This is a list of supplementary files associated with this preprint. Click to download.

- SupplementTable1.docx 